\title{
A study on effect of melatonin in dyslipidemia caused by experimentally diabetes
}

\author{
Deniz ULUIŞIK ${ }^{1}$, Ercan KESKIN ${ }^{1}$, Durmuş HATIPOĞLU1
}

\author{
${ }^{1}$ Department of Physiology, Faculty of Veterinary Medicine, \\ University of Selcuk, Konya, Turkey \\ Address Correspondence to D. ULUIŞIK, e-mail: aytekin.alpullu@marmara.edu.tr
}

\begin{abstract}
In this study, it was aimed to determine the effects of melatonin application on lipid profile in streptozotocin-induced diabetic rats. Animals in control group were not any treatment. Melatonin group animals received $50 \mathrm{mg} / \mathrm{kg}$ melatonin intraperitoneally in daily for eight weeks. Diabetes was induced by subcutaneous injections of streptozotocin at dose of $40 \mathrm{mg} / \mathrm{kg}$ for two days as a single dose per day in diabetes group animals. Animals in Diabetes+Melatonin group were made diabetic by streptozotocin in the same way and then these animals received $50 \mathrm{mg} / \mathrm{kg}$ melatonin intraperitoneally in daily for eight weeks. In blood samples taken from all animals, TNF- $\alpha$, triglyceride, total cholesterol, LDL and HDL were determined. In diabetes group, TNF- $\alpha$ level were high $(\mathrm{p}<0.05)$. The changes in TNF- $\alpha$ level with melatonin application to diabetic rats were important $(\mathrm{p}<0.05)$. In diabetic rats, triglyceride and LDL levels were found to be enhanced compared to control group $(\mathrm{p}<0.05)$, HDL level was significantly low $(\mathrm{p}<0.05)$, while the change in total cholesterol level was not important. With the melatonin application to diabetic rats, HDL level was found to be higher $(p<0.05)$ and LDL level was lower than diabetes group $(p<0.05)$. It was concluded that the administration of melatonin to streptozotocin-induced diabetic rats may have positive effects on lipid profile.
\end{abstract}

Key words: Diabetes, melatonin, TNF- $\alpha$, lipid profile, rats.

\section{INTRODUCTION}

Diabetes has serious complications in worldwide and its incidence is an increasing in recent years. Cardiovascular disorders are one of the most important complications of diabetes. The incidence of cardiovascular disorders in diabetic patients is 3-4 times higher than those without diabetes. Several risk factors such as dyslipidemia, hypertension and smoking are thought to be associated with the prevalence of micro and macrovascular disorders in diabetes. It is accepted that diabetes itself is an independent risk factor for development of atherosclerosis cases. Oxidative stress is one of the potential mechanisms that mediate vascular disorders in diabetes. Free radicals and oxidative stress play an important role in atherogenesis as well as cause oxidation of low density lipoproteins. Oxidized LDL (Ox-LDL) is recognized not only by LDL receptors but also by the cleansing receptor pathway in macrophages, which results in foam cell formation resulting in irregular cholesterol accumulation $(14,33)$.

Blood lipids are mainly cholesterol, triglycerides, phospholipids and free fatty acids. Hyperlipidemia plays an important role in the development of many cardiovascular disorders such as atherosclerosis, angina pectoris, myocardial infarction and stroke (16). Excessive inflammatory fibroproliferative events in response to various conditions lead to atherosclerotic lesions by damaging the arterial wall smooth muscles and endothelium (23). Increased lipid accumulation in vascular endothelium is one of the factors that trigger inflammatory processes (16). It is suggested that increased C-reactive protein (CRP) and TNF- $\alpha$ due to hyperlipidemia are closely related to the onset of the inflammatory process and thus antiinflammatory applications against hyperlipidemia may be effective (26). There are also reports that inflammatory events independent from hyperlipidemia are associated with the onset of atherosclerosis (35).

The increase in obesity and adipose tissue caused by diabetes leads to an increase in releasing of peptides such as leptin, adiponectin and vaspin from these tissues, while it is also observed the increase in production of some proinflammatory cytokines in the same tissues $(18,22,41)$. It has been reported that interleukin-6 (IL-6) and TNF- $\alpha$ are released from adipose tissue and its plasma levels increase in parallel with adipose tissue increase (11, 25). In addition, it was claimed that there is a 
correlation between these inflammatory cytokines and both endothelial dysfunction and the development of atherosclerosis $(8,49)$.

Melatonin, known as the hormone of darkness, has an important role in various functions on metabolic events as well as the regulation of the biological rhythm (31). It has been suggested that melatonin modulate lipoprotein metabolism and improve the negative changes in plasma triglyceride, total cholesterol, LDL and HDL levels in diabetic patients. On the other hand, it was suggested that melatonin has hypocholesterolemic effect by reducing cholesterol absorption from the intestines (12). It has been reported that melatonin administration to diabetic rats has positive effects on changes in plasma and erythrocyte GSH, triglyceride, cholesterol and HDL levels (28).

The aim of this study was to determine the effects of melatonin application on changes in plasma lipid profile caused by streptozotocininduced diabetes.

\section{MATERIAL AND METHOD}

In this study, 32 adult male Wistar Albino rat was used. Rats were kept in proper conditions (heat, humidity and light) during the study period. The animals were divided into four groups. Standard rat diet was fed ad libitum to animals in all groups for 8 weeks. No application was made to animals in control group $(K, n=6)$. The animals in the melatonin $(\mathrm{M}, \mathrm{n}=6)$ group were intraperitoneally injected 50 $\mathrm{mg} / \mathrm{kg}$ melatonin (Sigma-Aldrich, St. Louis, MO, USA) every day for 8 weeks. In diabetes group (D, $\mathrm{n}=9$ ), diabetes was induced by subcutaneous injections of streptozotocin (Sigma-Aldrich, St. Louis, MO, USA) at dose of $40 \mathrm{mg} / \mathrm{kg}$ in $0.1 \mathrm{M}$ citrate buffer ( $\mathrm{pH} 4.5$ ) for two days as a single daily dose. Animals in Diabetes+Melatonin group (DM, n=10) were made diabetic by application of streptozotocin in the same way and then were intraperitoneally injected with $50 \mathrm{mg} / \mathrm{kg}$ melatonin during 8 weeks. Six hours after streptozotocin administration, rats were orally received 5\% dextrose solution to prevent hypoglycemia for 3 days. One week after the streptozotocin injection, blood glucose levels were measured by glycometer (PlusMED Accuro, Taiwan) and rats which have $250 \mathrm{mg} / \mathrm{dl}$ or high blood glucose levels were included in the diabetic groups (group D and DM). One animal from the diabetes group died due to hypoglycemia during the study. At the end of 8 weeks, the TNF- $\alpha$, Triglyceride, Total
Cholesterol, LDL and HDL levels were determined in blood samples.

TNF- $\alpha$ level were determined with ELISA (Biotek ELx800, Biotek Instrumentations, Inc, Winooski, VT, USA) using sandwich enzyme-linked immunosorbent method via commercial kits (Elabscience), while Triglyceride, Total Cholesterol, LDL and HDL levels were determined the Abbott C8200 autoanalyzer using Abbott kits.

The data obtained from the study were analyzed by one-way ANOVA (SPSS 19). Differences among the groups were determined by Duncan's multiple range test. Differences were considered significant at $\mathrm{p}<0.05$. The study protocol was approved by The Ethical Committee of Selcuk University Experimental Medicine Research and Application Center (Report no. 2017-15).

\section{RESULTS}

The effects of melatonin administration on plasma total cholesterol, triglyceride, some lipoprotein levels and TNF- $\alpha$ in streptozotocin-induced diabetic rats are summarized in Table 1.

TNF- $\alpha$, a proinflammatory cytokine, was found to be significantly higher in diabetes group than the control group (Table 1, p<0.05), whereas it was significantly lower in melatonin administrated diabetic rats than in the diabetes group (Table 1, $\mathrm{p}<0.05)$. In the study, it was determined that plasma triglyceride level was significantly higher in rats with experimental diabetes than the control group (Table $1, \mathrm{p}<0.05)$. In diabetic rats, decrease in plasma HDL level (Table 1, $\mathrm{p}<0.05$ ) and increase in LDL level (Table $1, \mathrm{p}<0.05$ ) were found to be significant compared to the control group, but the increase in total cholesterol level was not significant. With 50 $\mathrm{mg} / \mathrm{kg}$ melatonin administration to diabetic rats, plasma HDL level were found to be significantly higher compared to diabetic animals (Table 1, $\mathrm{p}<0.05)$ and LDL level were significantly lower than in diabetic animals (Table $1, \mathrm{p}<0.05$ ). The changes in plasma total cholesterol and triglyceride levels with melatonin administration to diabetic rats were not important when compared to diabetes group. 
Table 1. Effect of melatonin on total cholesterol, triglyceride, LDL, HDL and TNF- $\alpha$ levels in streptozotocin-induced diabetic rats $($ Mean \pm SE).

\begin{tabular}{cccccc}
\hline & $\begin{array}{c}\text { Total Cholesterol } \\
(\mathrm{mg} / \mathrm{dl})\end{array}$ & $\begin{array}{c}\text { Triglyceride } \\
(\mathrm{mg} / \mathrm{dl})\end{array}$ & $\begin{array}{c}\text { LDL } \\
(\mathrm{mg} / \mathrm{dl})\end{array}$ & $\begin{array}{c}\text { HDL } \\
(\mathrm{mg} / \mathrm{dl})\end{array}$ & $\begin{array}{c}\text { TNF- } \alpha \\
(\mathrm{pg} / \mathrm{ml})\end{array}$ \\
\hline $\mathrm{K}$ & $87.33 \pm 6.63^{\mathrm{ab}}$ & $62.50 \pm 5.13^{\mathrm{b}}$ & $43.83 \pm 1.877^{\mathrm{bc}}$ & $39.67 \pm 3.65^{\mathrm{a}}$ & $91.54 \pm 3.96^{\mathrm{c}}$ \\
\hline $\mathrm{M}$ & $80.83 \pm 6.29^{\mathrm{b}}$ & $61.17 \pm 7.31^{\mathrm{b}}$ & $39.50 \pm 1.18^{\mathrm{c}}$ & $44.50 \pm 4.96^{\mathrm{a}}$ & $89.28 \pm 7.14^{\mathrm{c}}$ \\
\hline $\mathrm{D}$ & $105.50 \pm 4.92^{\mathrm{a}}$ & $86.50 \pm 5.16^{\mathrm{a}}$ & $64.90 \pm 3.93^{\mathrm{a}}$ & $28.10 \pm 3.43^{\mathrm{b}}$ & $127.49 \pm 5.35^{\mathrm{a}}$ \\
\hline $\mathrm{DM}$ & $92.11 \pm 6.27^{\mathrm{ab}}$ & $79.56 \pm 7.09^{\mathrm{ab}}$ & $51.78 \pm 4.70^{\mathrm{b}}$ & $41.78 \pm 3.46^{\mathrm{a}}$ & $109.42 \pm 4.56^{\mathrm{b}}$ \\
\hline
\end{tabular}

a-c The difference between mean values with different superscripts in the same column is significant at the $\mathrm{p}<0.05$ level

\section{DISCUSSION}

Diabetes affecting millions of people worldwide is characterized by high blood glucose levels, insulin resistance or insufficiency. Some of the complications responsible for the mortality are considered as triopaty (retinopathy, neuropathy and nephropathy), dyslipidemia and cardiovascular diseases $(5,39)$. In recent years, there has been a growing interest in the use of various alternative products for the treatment and prevention of diabetes $(3,4,20,39$, 42). Melatonin depend on its many physiological effects has been used as an option in preventions of diabetes and its complications $(28,43)$.

TNF- $\alpha$ is a proinflammatory cytokine which is produced by macrophages and adipose tissue. The plasma level of TNF- $\alpha$ is reported to be high in diabetes studies conducted in human and rat $(6,10$, $13,15,32,40,46)$. It is stated that TNF- $\alpha$ production and release increased in response to systemic inflammation plays a role in dyslipidemia and vascular pathophysiology related to diabetes (44, 45). It is reported that increased TNF- $\alpha$ in diabetes further exacerbates the current situation by inhibiting the kinase activities that form the insulin signaling pathway in skeletal muscles, fat tissue, endothelial cells and other tissues $(1,37)$. It has been shown that TNF- $\alpha$ increase the levels of triglyceride and very low density lipoprotein (VLDL) as it affects lipolysis in mouse, rat and human fat cells $(13,36$, 49). One of the best known properties of melatonin, also known as the hormone of darkness, is reported as its effect on anti-inflammatory mechanisms (43). It has been suggested that melatonin inhibits proinflammatory cytokines in polymorphic nuclear leukocytes, endothelial cells and colitis, thereby alleviating tissue damage and cell migration due to inflammation $(17,30,43)$. The effects of melatonin on proinflammatory cytokines, especially TNF- $\alpha$, are attributed to the inhibition of mRNA expression of these cytokines (21). In paralelly, administration of oral melatonin has been reported to modulate overexpression of TNF- $\alpha(9,38)$. The decrease in plasma TNF- $\alpha$ level with melatonin administration to diabetic rats can be explained with the mechanisms stated above. The TNF- $\alpha$ level in diabetic animals treated with melatonin was still higher than both control and melatonin group levels. This can be accepted a sign of systemic inflammation relatively continouied due to diabetes.

Plasma triglyceride levels were significantly higher in rats with experimentally induced diabetes than the control group (Table 1, $\mathrm{p}<0.05$ ). In diabetic rats, decrease in plasma HDL level (Table 1, $\mathrm{p}<0.05$ ) and increase in LDL level (Table 1, p<0.05) were found to be significant compared to the control group. With $50 \mathrm{mg} / \mathrm{kg}$ melatonin administration to diabetic rats, plasma HDL level were found to be significantly higher compared to diabetic animals (Table 1, p<0.05) and LDL level were significantly lower than in diabetic animals (Table 1, p<0.05). Melatonin administration to rats with diabetes resulted in obviously improving HDL and LDL levels but the effects of melatonin on plasma triglyceride and total cholesterol levels were found to be limited. There are some reports that hyperglycemia generally caused hypertriglyceridemia and hypercholesterolemia (48). The findings obtained from our study appear to be consistent with the data of researches conducted on the same subject $(19,24,48)$. The positive changes observed in the plasma lipid parameters by the administration of melatonin are attributed to the reasons such as suppressed tissue lubrication (34, 47), increased lipoprotein lipase activity and increased insulin sensitivity resulting in decreased 
of lipolysis in adipose tissue (34). Mechanisms such as inhibition of cholesterol absorption (12) and synthesis (2), increased conversion of cholesterol to bile acids, increased LDL receptor activity $(2,29)$, and inhibition of metabotropic receptors involved in the transport of fatty acids (7) are considered among the corrective effects of melatonin on the lipid profile (27).

\section{CONCLUSION}

When considering significant changes obtained in TNF- $\alpha$, HDL and LDL levels with melatonin application and partial positive changes in total cholesterol and triglyceride levels, it was thought that melatonin application might have a corrective effect on dyslipidemia seen in diabetes.

\section{ACKNOWLEDGMENT}

This study was supported by Selçuk University Scientific Research Projects Coordination Unit (Proje No: 17401132).

\section{REFERENCES}

1. Baud V, Karin M. Signal transduction by tumor necrosis factor and its relatives. Trends Cell Biol, 2001; 11(9): 372-377.

2. Chan TY, Tang PL. Effect of melatonin on the maintenance of cholesterol homeostasis in the rat. Endocr Res, 1995; 21(3): 681-696.

3. Chang CL, Lin Y, Bartolome AP, Chen YC, Chiu SC, Yang WC. Herbal therapies for type 2 diabetes mellitus: Chemistry, biology, and potential application of selected plants and compounds. Evid Based Complement Alternat Med, 2013, 2013: 378657.

4. Chen J, Mangelinckx S, Adams A, Wang ZT, Li WL, De Kimpe N. Natural flavonoids as potential herbal medication for the treatment of diabetes mellitus and its complications. Nat Prod Commun, 2015; 10(1): 187-200.

5. Chen SC, Tseng CH. Dyslipidemia, kidney disease, and cardiovascular disease in diabetic patients. Rev Diabet Stud, 2013; 10(2-3): 88-100.

6. Dandona P, Aljada A. A rational approach to pathogenesis and treatment of type 2 diabetes mellitus, insulin resistance, inflammation, and atherosclerosis. Am J Cardiol, 2002; 90(5A): 27-33.

7. Dauchy RT, Blask DE, Sauer LA, Davidson LK, Krause JA, Smith LC, Dauchy EM. Physiologic melatonin concentration, omega-3 fatty acids, and conjugated linoleic acid inhibit fatty acid transport in rodent hind limb skeletal muscle in vivo. Comp Med, 2003; 53(2): 186-190.

8. Festa A, D'Agostino R Jr, Howard G, Mykkänen L, Tracy RP, Haffner SM. Chronic subclinical inflammation as part of the insulin resistance syndrome: the Insulin Resistance Atherosclerosis Study (IRAS). Circulation, 2000; 102: 42-47.

9. Haddadi GH, Fardid R. Oral administration of melatonin modulates the expression of tumor necrosis factor- $\alpha$ (TNF- $\alpha$ ) gene in irradiated rat cervical spinal cord. Rep Pract Oncol Radiother, 2015; 20(2): 123-127.
10. Halse R, Pearson SL, McCormack JG, Yeaman SJ, Taylor R. Effects of tumor necrosis factor-alpha on insulin action in cultured human muscle cells. Diabetes, 2001; 50(5): 1102-1109.

11. Hotamisligil GS. Mechanisms of TNF-alpha-induced insulin resistance. Exp Clin Endocrinol Diabetes, 1999; 107: 119-125.

12. Hussain SA. Effect of melatonin on cholesterol absorption in rats. J Pineal Res, 2007; 42(3): 267-271.

13. Jain SK, Rains JL, Croad JL. Effect of chromium niacinate and chromium picolinate supplementation on lipid peroxidation, TNF-alpha, IL-6, CRP, glycated hemoglobin, triglycerides, and cholesterol levels in blood of streptozotocin-treated diabetic rats. Free Radic Biol Med, 2007; 43(8): 1124-1131.

14. Jialal I, Devaraj S, Venugopal SK. Oxidative stress, inflammation, and diabetic vasculopathies: the role of alpha tocopherol therapy. Free Radic Res, 2002; 36(12): 1331-1336.

15. Jialal I, Devaraj S, Venugopal SK. C-reactive protein: risk marker or mediator in atherothrombosis. Hypertension, 2004; 44(1): 6-11.

16. Joo IIW, Ryu JH, Oh HJ. The Influence of Sam-Chil-Geun (Panax Notoginseng) on the Serum Lipid Levels and Inflammations of Rats with Hyperlipidemia Induced by Poloxamer-407. Yonsei Med J, 2010; 51(4): 504-510.

17. Keshavarzian A, Morgan G, Sedghi S, Gordon JH, Doria M. Role of reactive oxygen metabolites in experimental colitis. Gut, 1990; 31(7): 786-790.

18. Kim JH, Hahm DH, Yang DC, Kim JH, Lee HJ, Shim I. Effect of Crude Saponin of Korean Red Ginseng on High-Fat DietInduced Obesity in the Rat. J Pharmacol Sci, 2005; 97(1): 124131.

19. Lee J, Lee HI, Seo KI, Cho HW, Kim MJ, Park EM, Lee MK. Effects of ursolic acid on glucose metabolism, the polyol pathway and dyslipidemia in non-obese type 2 diabetic mice. Indian J Exp Biol, 2014; 52(7): 683-691.

20. Li GQ, Kam A, Wong KH, Zhou X, Omar EA, Alqahtani A, Li KM, Razmovski-Naumovski V, Chan K. Herbal medicines for the management of diabetes. Adv Exp Med Biol, 2012; 771: 396-413.

21. Li JH, Yu JP, Yu HG, Xu XM, Yu LL, Liu J, Luo HS. Melatonin reduces inflammatory injury through inhibiting NF-kappaB activation in rats with colitis. Mediators Inflamm, 2005; 2005(4): 185-193.

22. Li Q, Chen R, Moriya J, Yamakawa J, Sumino H, Kanda T, Takahashi T. Novel Adipocytokine, Visceral Adipose Tissuederived Serine Protease Inhibitor (Vaspin), and Obesity. J Int Med Res, 2008; 36: 625-629.

23. Libby P. Inflammation in atherosclerosis. Nature, 2002; 420: 868-874.

24. Lo CC, Lin SH, Chang JS, Chien YW. Effects of melatonin on glucose homeostasis, antioxidant ability, and adipokine secretion in ICR mice with NA/STZ-induced hyperglycemia. Nutrients, 2017; 9(11): 1187.

25. McCarty MF. Interleukin-6 as a central mediator of cardiovascular risk associated with chronic inflammation, smoking, diabetes, and visceral obesity: down-regulation with essential fatty acids, ethanol and pentoxifylline. Med Hypotheses, 1999; 52: 465-477.

26. Micallef MA, Garg ML. Anti-inflammatory and cardioprotective effects of n-3 polyunsaturated fatty acids and plant sterols in hypertlipidemic individuals. Atherosclerosis, 2009; 204: 476-482.

27. Mohammadi-Sartang M, Ghorbani M, Mazloom Z. Effects of melatonin supplementation on blood lipid concentrations: A systematic review and meta-analysis of randomized controlled trials. Clin Nutr, 2018; 37(6 Pt A): 1943-1954.

28. Montilla PL, Vargas JF, Tlinez IF, Muñoz de Agueda MC, Valdelvira ME, Cabrera ES. Oxidative stress in diabetic rats 
induced by streptozotocin: Protective effects of melatonin. J Pineal Res, 1998; 25(2): 94-100.

29. Müller-wieland D, Behnke B, Koopmann K, Krone W. Melatonin inhibits LDL receptor activity and cholesterol synthesis in freshly isolated human mononuclear leukocytes. Biochem Biophysical Res Commun, 1994; 203(1): 416-421.

30. Nosalova V, Michal Z, Cerna S, Navarova J, Zakalova M. Protective effect of melatonin in acetic acid induced colitis in rats. J Pineal Res, 2007; 42(4): 364-370.

31. Pandi-Perumal SR, Srinivasan V, Maestroni GJ, Cardinali DP, Poeggeler B, Hardeland R. Melatonin: Nature's most versatile biological signal?. FEBS J, 2006; 273(13): 2813-2838.

32. Peraldi $P$, Spiegelman B. TNF-alpha and insulin resistance: summary and future prospects. Mol Cell Biochem, 1998; 182(1-2): 169-175.

33. Rahimi R, Nikfar S, Larijani B, Abdollahi M. A review on the role of antioxidants in the management of diabetes and its complications. Biomed Pharmacother, 2005; 59: 365-373.

34. Rasmussen DD, Boldt BM, Wilkinson CW, Yellon SM, Matsumoto AM. Daily melatonin administration at middle age suppresses male rate visceral fat, plasma leptin, and plasma insulin to youthful levels. Endocrinology, 1999; 140(2): 1009-1012.

35. Ridker PM, Silvertown JD. Inflammation, C-reactive protein, and atherothrombosis. J Periodontol, 2008; 79: 1544-1551.

36. Rosenstock M, Greenberg AS, Rudich A. Distinct long-term regulation of glycerol and non-esterified fatty acid release by insulin and TNF-alpha in 3T3-L1 adipocytes. Diabetologia, 2001; 44(1): 55-62.

37. Rui L, Aguirre V, Kim JK, Shulman GI, Lee A, Corbould A, Dunaif A, White MF. Insulin/IGF-1 and TNF-alpha stimulate phosphorylation of IRS-1 at inhibitory Ser307 via distinct pathways. J Clin Invest, 2001; 107(2): 181-189.

38. Sánchez A, Calpena AC, Clares B. Evaluating the oxidative stress in inflammation: role of melatonin. Int J Mol Sci, 2015; 16(8): 16981-17004.

39. Sasaki M, Nishida N, Shimada M. A Beneficial Role of Rooibos in Diabetes Mellitus: A Systematic Review and MetaAnalysis. Molecules, 2018; 23(4): pii: E839.

40. Schmidt MI, Duncan BB. Diabesity: an inflammatory metabolic condition. Clin Chem Lab Med, 2003; 41(9): 11201130.

41. Stanley S, Wynne K, Mcgowan B, Bloom S. Hormonal Regulation of Food Intake. Physiol Rev, 2005; 85: 1131-1158.

42. Suksomboon N, Poolsup N, Boonkaew S, Suthisisang CC. Meta-analysis of the effect of herbal supplement on glycemic control in type 2 diabetes. J Ethnopharmacol, 2011; 137(3): 1328-1333.

43. Tahan G, Gramignoli R, Marongiu F, Aktolga S, Cetinkaya A, Tahan V, Dorko K. Melatonin expresses powerful antiinflammatory and antioxidant activities resulting in complete improvement of acetic-acid-induced colitis in rats. Dig Dis Sci, 2011; 56(3): 715-720.

44. Ugochukwu NH, Figgers CL. Caloric restriction inhibits upregulation of inflammatory cytokines and TNF-alpha, and activates IL-10 and haptoglobin in the plasma of streptozotocin-induced diabetic rats. J Nutr Biochem, 2007; 18(2): $120-126$.

45. Vicente R, Coma M, Busquets S, Moore-Carrasco R, LópezSoriano FJ, Argilés JM, Felipe A. The systemic inflammatory response is involved in the regulation of $\mathrm{K}(+)$ channel expression in brain via TNF-alpha-dependent and independent pathways. FEBS Lett, 2004; 572(1-3): 189-194.

46. Wellen KE, Hotamisligil GS. Inflammation, stress, and diabetes. J Clin Invest, 2005; 115(5): 1111-1119.
47. Wolden-Hanson T, Mitton DR, McCants RL, Yellon SM, Wilkinson CW, Matsumoto AM, Rasmussen DD. Daily melatonin administration to middle-aged male rats suppresses body weight, intraabdominal adiposity, and plasma leptin and insulin independent of food intake and total body fat. Endocrinology, 2000; 141(2): 487-497.

48. Yuan G, Al-Shali KZ, Hegele RA. Hypertriglyceridemia: Its etiology, effects and treatment. CMAJ, 2007; 176(8): 1113-1120.

49. Yudkin JS, Stehouwer CD, Emeis JJ, Coppack SW. C-reactive protein in healthy subjects: associations with obesity, insulin resistance, and endothelial dysfunction: a potential role for cytokines originating from adipose tissue?. Arterioscler Thromb Vasc Biol, 1999; 19(4): 972-978. 